\title{
Some Problems in Surgical Management of Children with Hiatus Hernia
}

\author{
J. LARI and JAMES LISTER \\ From The Children's Hospital, Sheffield
}

\begin{abstract}
Lari, J., and Lister, J. (1972). Archives of Disease in Childhood, 47, 201. Some problems in surgical management of children with hiatus hernia. Thirtythree cases of hiatus hernia treated by operation in an 8-year period are reviewed. It is suggested that less delay in surgical intervention when a child is not responding to medical management might reduce the number of children who develop strictures as a result of gastro-oesophageal reflux and might improve the development of the child. Gastric fixation with gastrostomy not only improves the nutrition of a child before a major corrective procedure, but in a few cases may avoid more drastic operation. Though maximal acid secretion tests do not help to identify those cases likely to develop a stricture, it is, however, a useful procedure in indicating whether or not vagotomy should be added to fundal plication.
\end{abstract}

In the 8 years from 1963 to 1970, 33 children were operated on for hiatus hernia in the Sheffield Children's Hospital. It is likely that the total number attending the hospital with hiatus hernia will exceed those who are accurately diagnosed as such, but when the diagnosis is confined to those children in whom positive evidence of displacement of the cardio-oesophageal junction above the oesophageal hiatus, or herniation of intra-abdominal contents through the oesophageal hiatus is achieved by radiological, operative, or necropsy demonstration, then those cases coming to operation in Sheffield represented approximately one-third of all the hiatus hernias seen during the 8 years.

Of the 33 cases, there were 23 boys and 10 girls, and the hernias were classified as 26 sliding, 4 paraoesophageal or rolling ones, and 3 combined (Fig. 1). All the paraoesophageal hernias, whether simple rolling hernias or combined rolling and sliding ones, were treated by operation on diagnosis. The indications for operation in the sliding hernias were failure to thrive, persistent oesophagitis, or stricture. Operative procedures included pyloroplasty, gastric fixation, either by deliberate fixation of the lesser curve to the anterior abdominal wall or by incidental fixation of the anterior wall of the stomach to the abdominal wall in the process of making a gastrostomy, fundal plication (Nissen and Rossetti, 1959), and vagotomy with pyloroplasty (Fig. 2).

This is a small series of cases, but its study has

Received 20 September 1971. emphasized a number of points in the management of this condition.

\section{Associated Abnormalities (Table I)}

Two children had oesophageal atresia with tracheo-oesophageal fistula; in these it would be

TABLE I

\section{Associated Anomalies}

\begin{tabular}{l|l}
\hline Pyloric stenosis & 2 \\
Mental retardation & 3 \\
Oesophageal atresia with tracheo- & 2 \\
$\quad$ oesophageal fistula & 1 \\
Congenital heart (VSD) & 1 \\
Cleft palate & 1 \\
\hline
\end{tabular}

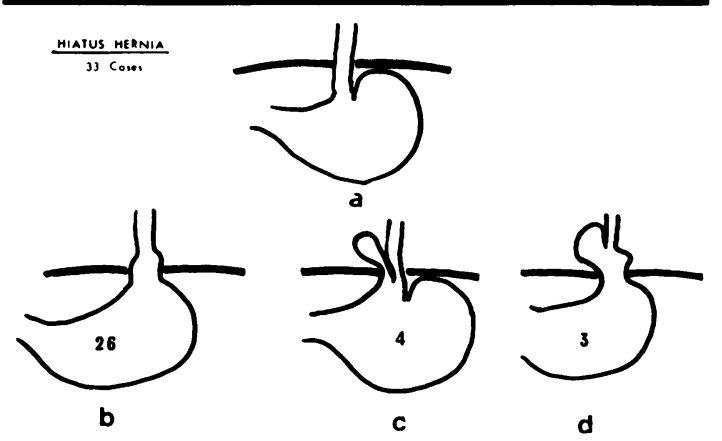

Fig. 1.-Hiatus hernia 33 cases. (a) Normal, (b) sliding 26, (c) paraoesophageal 4, (d) combination of paraoesophageal and sliding 3. 


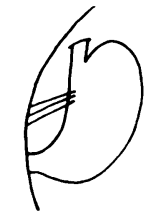

GASIROPEXY
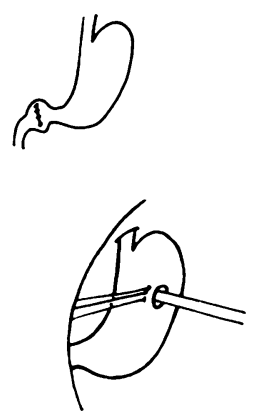

GASIROSIOMY
FUNDAL PLICAIION

VAGOIOMY ANR PYLOROPLASIY
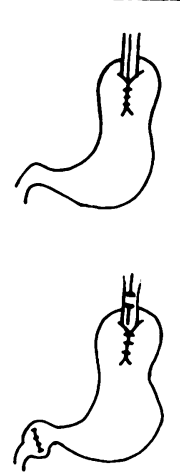

FIG. 2.-Types of operation.

not unreasonable to attribute the hiatal hernia to the mobilization of the lower pouch at the time of anastomosis of the oesophagus. 3 children were mentally retarded, but none of them showed the sucrosuria that was found by Moncrieff and Wilkinson (1954). 2 children had pyloric stenosis, one a cleft palate, and one choanal atresia; these patients, particularly those with pyloric stenosis, could possibly have the vomiting with the associated anomaly blamed for the development of the hiatus hernia (Waterston, 1962). In a further 3 patients preoperative $x$-rays showed delay in gastric emptying without demonstrable pyloric stenosis. One child had a ventricular septal defect.

\section{Gastric Fixation}

Two cases in the series showed a quite dramatic correction of an apparent severe oesophageal stricture by simple procedures. The first, already described by Lister and Wright (1967), was a 1-month-old boy admitted with dehydration and loss of weight due to a complete obstruction of the lower oesophagus. Oesophagoscopy revealed an impenetrable narrowing at the lower end of the

oesophagus, and a gastrostomy was made to feed him. Within 12 days the child was feeding orally and when he pulled his gastrostomy tube out it was not replaced, but instead oesophageal dilatations were performed on two occasions and a barium swallow 6 months later showed no narrowing (Fig. 3). Another older child (Case 2, Fig. 4) presented with severe vomiting, failure to respond to medical management, and $x$-ray had shown delay in gastric emptying and some apparent pyloric spasm. At operation pyloric stenosis was confirmed and a pyloroplasty was performed with a gastrostomy for feeding. There were a series of dilatations spread over 6 months, at one of which the oesophagus was perforated but healed with conservative treatment. The child's symptoms were completely relieved and she swallowed normally. A barium swallow showed no narrowing in the lower oesophagus and no evidence of hiatus hernia.

These 2 patients indicate that narrowing of the lower oesophagus has certainly not always been entirely due to fibrous stricture and there has been a large element of spasm and oedema. Other children, considerably debilitated by continuous unrelieved vomiting, who had not been considered fit to undergo a major procedure, had gastrostomies made for feeding, and showed the same relaxation of their oesophageal narrowing with consequent improvement in swallowing. From these cases it was presumed that gastrostomy was possibly acting rather like a gastropexy by fixing the stomach to the anterior abdominal wall and discouraging upward displacement of the cardia and consequent gastro-oesophageal reflux; this seemed a more likely explanation than that the oesophagus was being 'rested' by formation of a gastrostomy. Gastrostomies were therefore performed as a deliberate primary procedure in a number of cases, not only to improve the child's general condition, but also to elucidate the amount of the lower oesophageal narrowing which might be due to spasm and to show the few cases in which an irreversible fibrous stricture had developed.

Fourteen patients had gastric fixation (Table II) 12 of them having fixation performed with a gastrostomy and 2 having a gastropexy alone. 3 of these patients did well after this procedure; 2 of them had gastrostomies made because of apparent

TABLE II

Results of Gastric Fixation

\begin{tabular}{l|l|l}
\hline Gastric fixation & 14 & $\begin{array}{r}3 \text { well } \\
1 \text { died } \\
10 \text { further treatment necessary }\end{array}$ \\
& & 14 \\
\hline
\end{tabular}



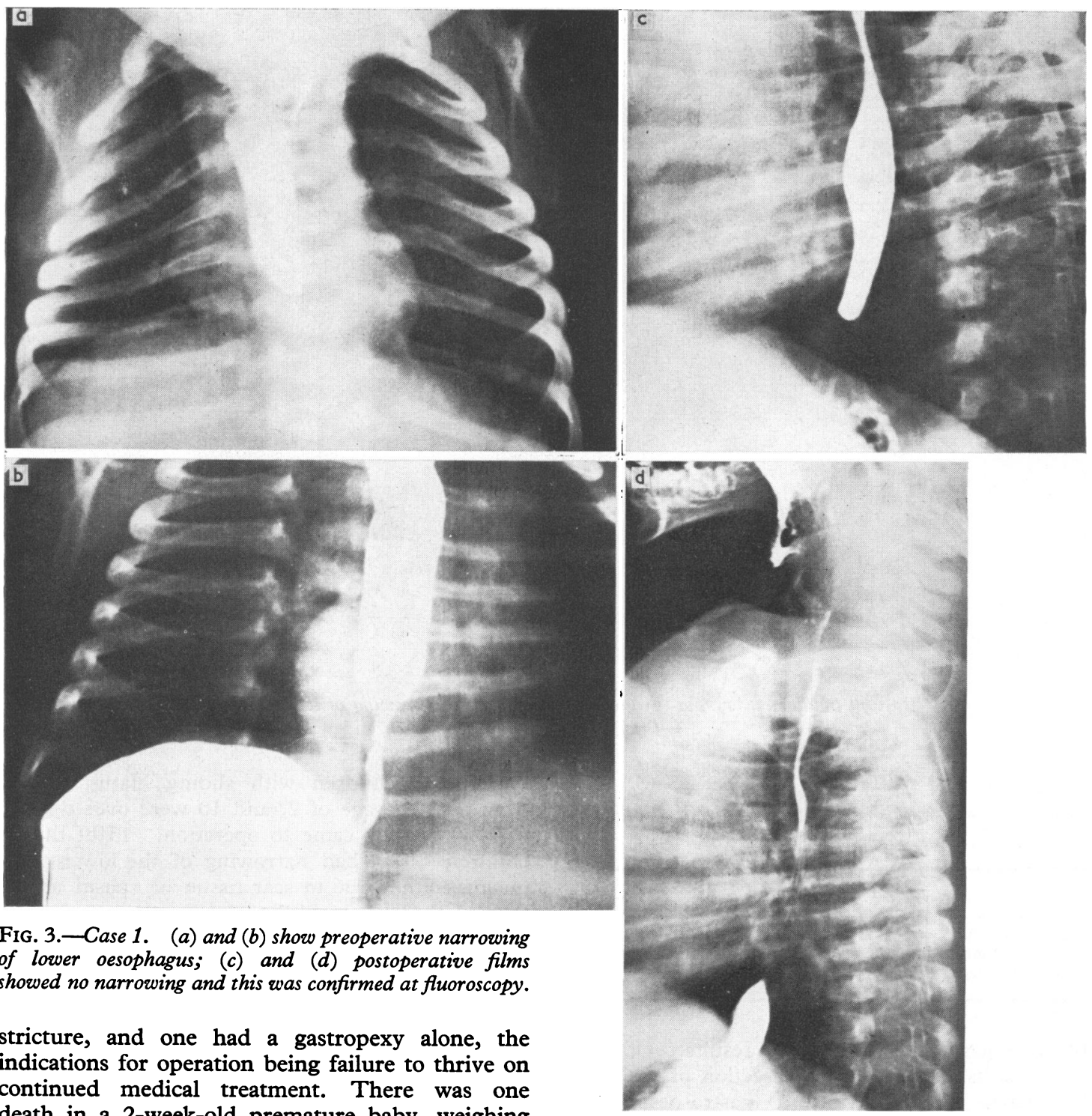

Fig. 3.-Case 1. (a) and (b) show preoperative narrowing of lower oesophagus; (c) and (d) postoperative films showed no narrowing and this was confirmed at fluoroscopy.

stricture, and one had a gastropexy alone, the indications for operation being failure to thrive on continued medical treatment. There was one death in a 2-week-old premature baby, weighing $1.7 \mathrm{~kg}$, in whom a gastrostomy was made for feeding purposes because of very severe prolonged vomiting; the child died immediately after his operation and necropsy showed a gross abnormality of the cervical part of the spinal cord, the cord being bifid. This abnormality may have played a large part in the child's continuous vomiting.

Of the remaining 10 cases, 6 have already had fundal plication with or without vagotomy and pyloroplasty and 4 are awaiting further operative treatment.

Clearly in our hands, a gastric fixation could not

be regarded as a successful definitive measure in the cure of the condition, but the three good results achieved indicate the value of this procedure in some cases, and gastrostomy for feeding purposes is a valuable procedure before the more extensive operation of fundal plication.

With regard to the more formal procedures, 16 fundal plications have been performed (Table III), 14 of them with a follow-up of over 6 months. 7 of these 14 cases had vagotomy and pyloroplasty in addition to their fundal plication, and 12 of the 


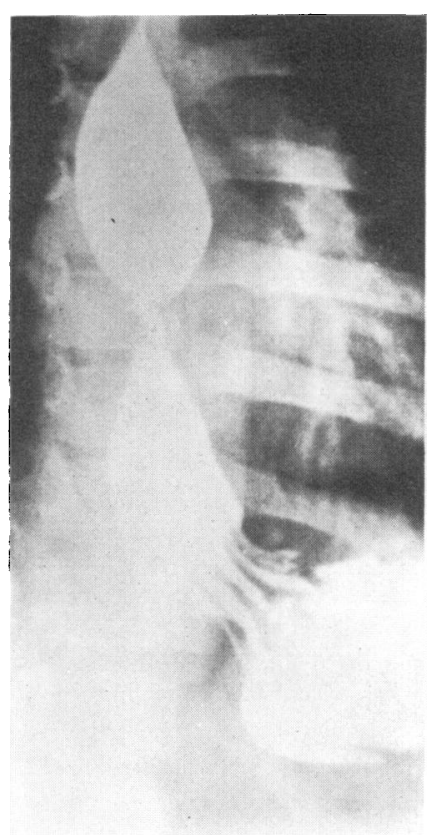

(a)

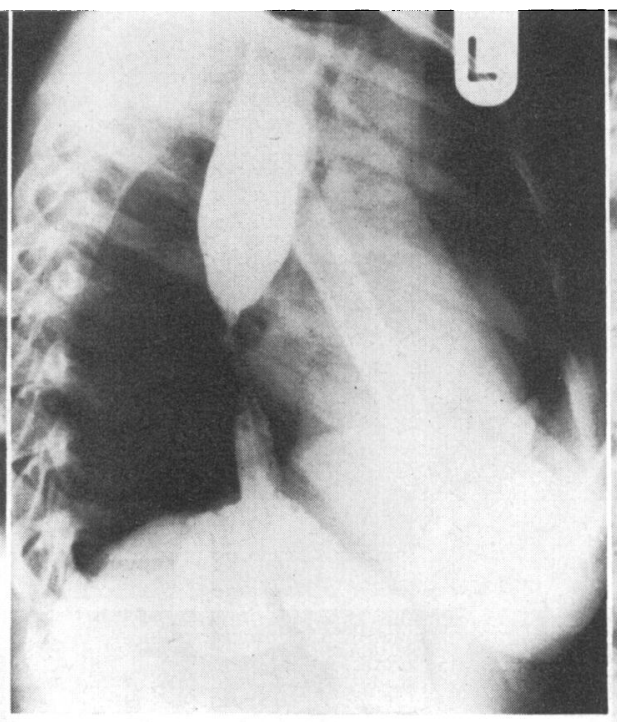

(b)

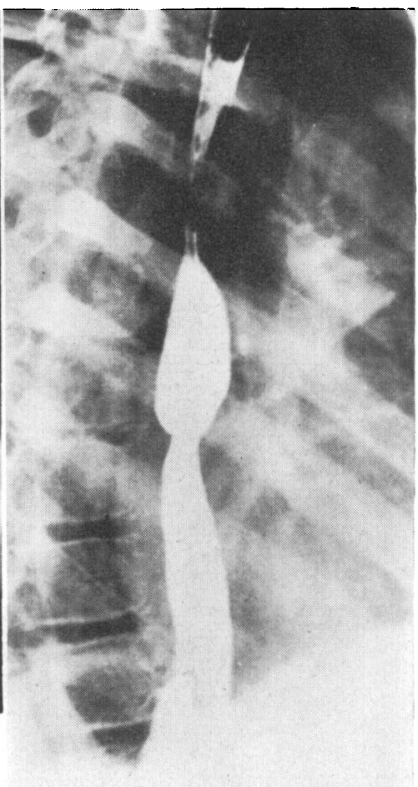

(c)

FIG. 4.-Case 2. Barium swallow. (a) and (b) preoperative-severe narrowing of lower oesophagus; (c) postoperative -the narrowing has improved.

TABLE III

Fundal Plication (Nissen) 14 Children: Follow-up for More than 6 Months

\begin{tabular}{l|c|c}
\hline \multicolumn{1}{c|}{ Type of Operation } & No. & Result \\
\hline $\begin{array}{l}\text { Fundal plication } \\
\begin{array}{l}\text { Fundal plication with vagotomy and } \\
\text { pyloroplasty }\end{array}\end{array}$ & 7 & 7 good \\
5 good \\
2 poor
\end{tabular}

14 are regarded as satisfactory results. Of the 2 poor results, both required resection of the lower oesophagus, one having a gastro-oesophageal anastomosis, and the other a colonic interposition.

\section{Timing of Surgical Intervention}

The weights of the children are shown in charts (Fig. 5) and are of some interest. Before operation all these children were below the 50th centile in weight. After operation some have come above this centile. The heights show a relatively normal scatter, though certainly some of these children were very small. On the whole one might say that the end result in the majority of cases is a thin child of normal height.
Half the children with sliding hiatus hernias were over the age of 2 , and 10 were over the age of 4 when they came to operation. 13 of the 26 children $(50 \%)$ had narrowing of the lower oesophagus, either due to scar tissue or spasm at the time of operation, and 7 of these were over 2 years of age.

Fibrous stricture formation is clear evidence of failure of conservative management, and an indication that surgical interference has been delayed too long. The fact that many of the children were underweight at the time of operation and below the 50th centile in spite of being asymptomatic after operation is possibly a further indication that operation should not be delayed unduly, say beyond the age of 2 years, when vomiting persists in spite of medical treatment.

\section{Acid Secretion Test}

The end results of surgical management in this series of cases compare reasonably with the results achieved in the management of hiatus hernia in adult surgery; one of the children died and two progressed to major oesophageal resections and may well have further trouble as they grow older. The 

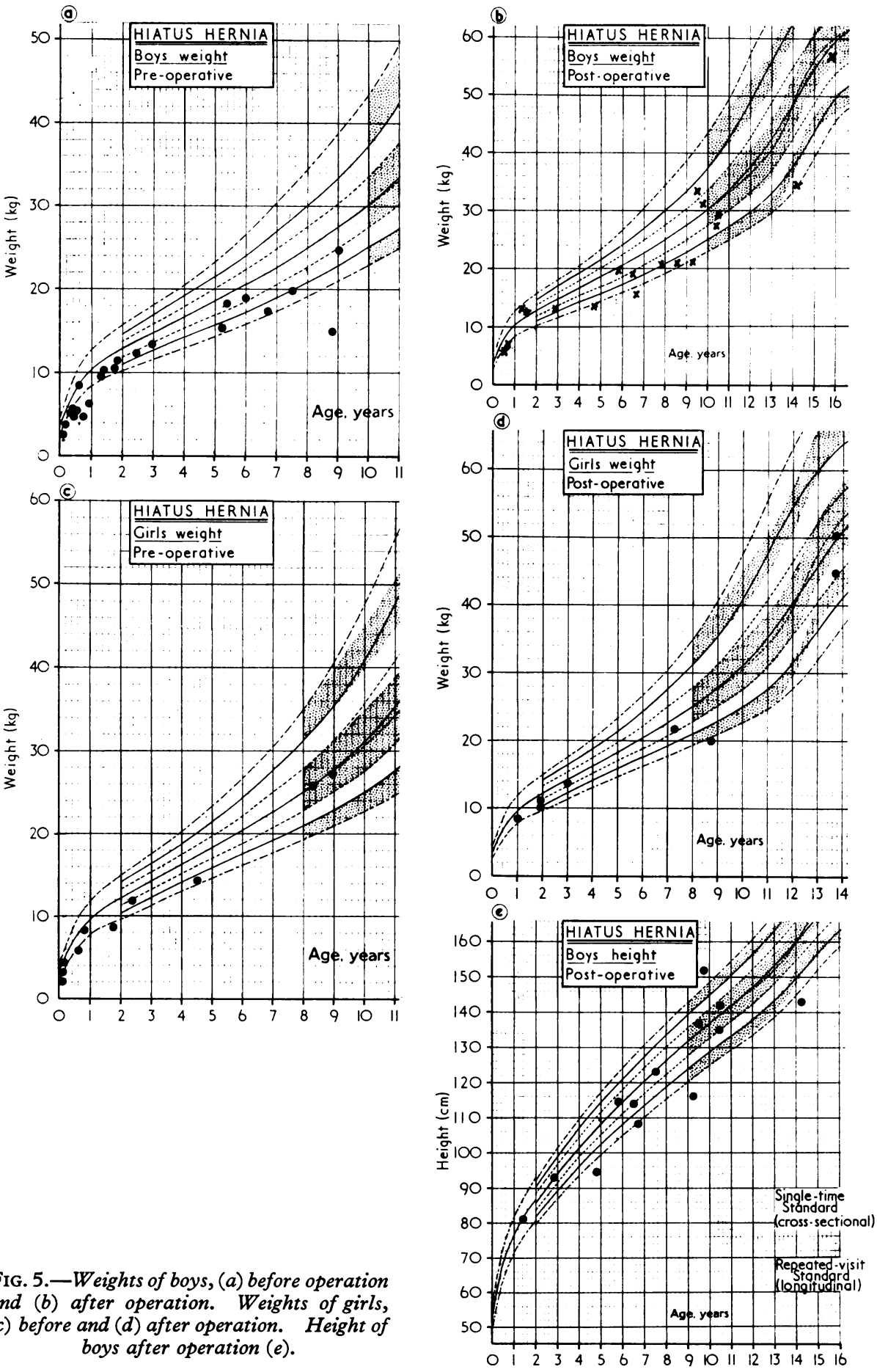

FIG. 5.-Weights of boys, (a) before operation and (b) after operation. Weights of girls, (c) before and (d) after operation. Height of boys after operation $(e)$. 
23 (88\%) who had satisfactory results encourage relatively early operation. The very bad results, as in most series of studies of hiatus hernia, are in children who developed fibrous stricture, and if the potential stricture former could be recognized operation might be recommended at an even earlier age. It was in an effort to detect these potential stricture formers that pentagastrin stimulated maximal acid secretion tests were introduced in these children (Lari, Lister, and Duthie, 1968). Further studies have been done since the previous report and are shown in Table IV. The mean peak acid secretion is shown in 17 controls, these being children with recurrent abdominal pain and a normal barium meal; in 21 children with hiatus hernia; in 11 children with duodenal ulcers; and in 41 normal adults. The figures show that the

TABLE IV

Comparisons of Peak Gastric Acid Secretion Age over 1 Year

\begin{tabular}{l|c|c}
\hline & No. & $\begin{array}{c}\text { Mean Peak Secretion } \\
\text { (mEq/10 kg per hr) }\end{array}$ \\
\hline Boys & 12 & $4 \cdot 71$ \\
Controls & 17 & $5 \cdot 49$ \\
Hiatus hernia & 7 & $5 \cdot 83$ \\
Duodenal ulcer & & \\
Girls & 5 & $4 \cdot 58$ \\
Controls & 4 & $5 \cdot 02$ \\
Hiatus hernia & 4 & $4 \cdot 29$ \\
Duodenal ulcer & 41 & $4 \cdot 22$ \\
\hline Normal adults & & \\
\hline
\end{tabular}

peak hourly output per $10 \mathrm{~kg}$ is similar in adults and children over 1 year. The children with hiatus hernia appear to produce a higher mean peak secretion, but this is not statistically significant, and in fact those children with hiatus hernia with a stricture did not show higher acid secretion than those without a stricture. This test therefore could not be regarded as being of use in recognizing the child who might develop oesophagitis severe enough to produce a fibrous stricture, but it has been used to decide whether vagotomy should be added to fundal plication when a major definitive operation is being contemplated. All those children who were shown to be high acid secretors had a vagotomy and pyloroplasty added to the plication procedure.

Fig. 3a, b, and d are reproduced with the kind permission of the Editor of the Proceedings of the Royal Society of Medicine.

\section{REFERENCES}

Lari, J., Lister, J., and Duthie, H. L. (1968). Response to gastrin pentapeptide in children. Fournal of Pediatric Surgery, 3, 682.

Lister, J., and Wright, T. (1967). Oesophageal stricture in the neonatal period. Proceedings of the Royal Society of Medicine, 60, 449.

Moncrieff, A., and Wilkinson, R. H. (1954). Sucrosuria with mental defect and hiatus hernia. Acta Paediatrica, 43, Suppl. $100,495$.

Nissen, R., and Rossetti, M. (1959). Die Behandlung von Hiatushernien und Reflux-ösophagitis mit Gastropexie and Fundoplicatio. Thieme, Stuttgart.

Waterston, D. J. (1962). Paediatric Surgery, Vol. 1, p. 303. Ed. by C. D. Benson et al. Yearbook Medical Publishers, Chicago.

Correspondence to Mr. James Lister, F.R.C.S., The Paediatric Surgical Unit, The Children's Hospital, Western Bank, Sheffield S10 2TH. 